\title{
OROPHARYNGEAL DYSPHAGIA IN PATIENTS WITH CHRONIC OBSTRUCTIVE PULMONARY DISEASE: A SYSTEMATIC REVIEW
}

\author{
Disfagia orofaríngea em pacientes com doença pulmonar \\ obstrutiva crônica: revisão sistemática
}

Lisa O’Kane (1), Michael Groher (2)

\begin{abstract}
Background: oropharyngeal dysphagia in patients with chronic obstructive pulmonary disease. Purpose: patients with Chronic Obstructive Pulmonary Disease (COPD) can be vulnerable to respiratory incompetence that may lead to swallowing impairment. A systematic review was conducted to investigate the relationship between Chronic Obstructive Pulmonary Disease and oropharyngeal dysphagia. Forty-seven articles were retrieved relating to Chronic Obstructive Pulmonary Disease and dysphagia. Each article was graded using evidence-based methodology. Only 7 articles out of the 47 addressed oropharyngeal swallowing disorders in patients with Chronic Obstructive Pulmonary Disease. This review found few studies that documented the relationship between oropharyngeal swallowing disorders and Chronic Obstructive Pulmonary Disease. There were no randomized control trials. Conclusion: although the evidence is not strong, it appears that patients with Chronic Obstructive Pulmonary Disease are prone to oropharyngeal dysphagia during exacerbations. Future studies are needed to document the prevalence of oropharyngeal dysphagia in homogeneous groups of patients with Chronic Obstructive Pulmonary Disease, and to assess the relationship between respiration and swallowing using simultaneous measures of swallowing biomechanics and respiratory function. These investigations will lead to a better understanding of the characteristics and risk factors of developing oropharyngeal dypshagia in patients with Chronic Obstructive Pulmonary Disease.
\end{abstract}

KEYWORDS: Pulmonary Disease, Chronic Obstructive; Deglutition Disorders; Review

\section{INTRODUCTION}

The coordinate interactions between breathing and swallowing are well known. They are linked physiologically as swallow interrupts respiration. Shared anatomic and physiologic substrates allow precise coordination of both events in tandem, and for a separation of function ${ }^{1}$. Shared commonalities include the location of neural control centers in the

(1) Speech-Language Patologist; Department of Communicative Disorders, University of Redlands, CA, USA; Spell Desorders.

(2) Speech-Language Patologist; Department of Communicative Disorders, University of Redlands, CA, USA; Degree in Bachelor of Arts with Honors in Comunicative Desorders; Ph.D., Professor and Chair.

Conflito de interesse: Inexistente medulla ${ }^{2}$, and shared anatomic structures such as the mouth, pharynx and larynx. Theoretically, interruption in breathing has the potential to interfere with swallowing. Most investigations that have examined the effects of disordered respiration on swallowing have studied patients with neurologic disease ${ }^{3-7}$. These studies have examined the interactionbetween disorderedbreathingandits effect on swallowing in patients with motor neuron disease ${ }^{3}$, spastic cerebral palsy ${ }^{5}$, and Parkinson's disease ${ }^{6}$. Interestingly, only one study sought to compare the breathing and swallowing performance in those with neuromuscular disease and in those with respiratory failure with tracheotomy ${ }^{4}$. Because patients with Chronic Obstructive Pulmonary Disease (COPD) may be liable to respiratory incompetence, swallowing also may be impaired. 
COPD is the fifth leading cause of death in North America ${ }^{8}$. By 2020 , the World Health Organization predicts it will be the third most diagnosed disease in the world and the fifth most disabling ${ }^{9}$. COPD usually encompasses subcategories of disease such as asthma, chronic bronchitis, emphysema, and airway obstruction. If respiratory compromise secondary to COPD impacts oropharyngeal swallowing safety, then the impact on one's quality of life would be greater if eating restrictions have to be imposed.

This systematic review sought to investigate the relationship between oropharyngeal swallowing disorders and COPD. We sought to answer the following questions: (1) what is the prevalence of oropharyngeal swallowing impairment in those with COPD? (2) what are characteristics of oropharyngeal swallowing disorders in patients with COPD? (3) what are the risk factors for developing oropharyngeal swallowing disorders in patients with COPD, and (4) is there any evidence that standard medical treatments for COPD improve oropharyngeal swallowing safety?

\section{METHODS}

A search for relevant literature in the English language between 1980 and 2008 was conducted using the following databases: PubMed, Medline, ComDis Dome, Cochrane Library, Agency for Healthcare Research and Quality, Campbell Collaboration, and the National Guideline Clearinghouse. No other limitations were placed on the search. Keywords used alone and in combination to gather relevant literature included: "respiratory disorders", "swallowing disorders", "dysphagia", "COPD" "deglutition", "gastroesophageal reflux disease", "complications", "oxygen saturation", "medications", and "meals". Hand searches were done on the reference lists of each article retrieved for additional relevant research.

Full text versions of articles retrieved were obtained. Articles were divided into five general sections: therapy/prevention, prognosis, diagnosis, differential diagnosis/symptom prevalence, and economic analysis. Each article was graded for the levelofevidenceusingtheOxfordCentreforEvidencebased Medicine's Levels of Evidence grading chart ${ }^{10}$ (Table 1). It was apparent that not all studies could be easily classified using the numerical scale due to overlap in design criteria. Therefore, letter grades (Column 1, Table 1) were assigned. Both authors independently assigned a level of evidence grade to each article. Interobserver agreement on assignment of the level of strength among two investigators was high (Kappa=.85).

\section{LITERATURE REVIEW}

\section{Levels of evidence}

A total of 47 articles were found and reviewed that related to COPD and swallowing $3-8,11-51$. Relevant articles were found between 1983 and 2008. Of the 47 articles, 8 were Level $A^{3,17-23} ; 27$ were Level B ${ }^{4-8,11,12,24-43 ;} 6$ were Level C ${ }^{36-41}$; and 6 were Level D ${ }^{16,47-51}$. Seven of the 47 articles investigated the relationship between COPD and oropharyngeal dysphagia $8,11-16$. These 7 articles were graded: no articles at Level A; 3 at Level $B^{8-12} ; 3$ at Level C ${ }^{13-15}$; and 1 at Level $D^{16}$.

\section{Review of subjects}

The 7 articles under review for this study included an average of 29 patients with COPD with a range

Table 1 - Study design and corresponding level of evidence. (SR=systematic review; RCT=randomized controlled trial.) Adapted from: Oxford Centre for Evidence-Based Medicine, 2001

\begin{tabular}{ccl}
\hline Evidence Grade & Level of Evidence & Type of Evidence \\
\hline A & $1 \mathrm{a}$ & SR of RCT's \\
$1 \mathrm{~b}$ & Individual RCT \\
$1 \mathrm{c}$ & All or None \\
& $2 \mathrm{a}$ & SR of Cohort Studies \\
$2 \mathrm{~b}$ & Individual Cohort Study \\
$\mathrm{2c}$ & Outcomes Research \\
B & $3 \mathrm{a}$ & SR of Case-Control Studies \\
& $3 \mathrm{~b}$ & Individual Case-Control Study \\
& 4 & Case Series (and poor quality case-control and \\
& & cohort studies) \\
Cxpert opinion without critical appraisal or based \\
\end{tabular}


from 14 to 78 . The study with 78 patients was a retrospective chart review ${ }^{13}$. When combined, the total subjects studied with COPD was 209. Only 2 of the 7 articles tested patients with COPD against a control group ${ }^{8,11}$. The age range in the experimental and control groups in the 7 studies was 18 to $88^{8,11-16}$. Excluding one study that did not provide data on the participant gender ${ }^{11}$, the 5 articles that reported on patients enrolled 162 males and 20 females ${ }^{8,12-15}$.

The most common exclusionary criteria in the reviewed articles included those with head and neck cancer, neuromuscular disease, esophageal disease, stroke, or central nervous system pathology ${ }^{8,12,13,15}$. Criteria that varied between studies were the exclusion of patients with tracheostomy ${ }^{8,13}$, current smokers ${ }^{12}$, and respiratory disorders other than COPD $^{8}$.

In 3 of the 6 studies that tested patients with COPD, subjects were referred because oropharyngeal dysphagia had been identified or there was a high suspicion for its presence ${ }^{13-15}$. The remaining 3 studies did not select patients suspected of dysphagia, but did assess them for possible disorders of swallowing ${ }^{8,11,12}$. While most studies had similar subject exclusionary criteria, comparison across studies is difficult because some patients had tracheostomy ${ }^{8,13}$, ventilator dependency ${ }^{18}$, gastrostomy and nasogastric tubes ${ }^{15}$, lung hyperinflation ${ }^{8}$ and gastroesophageal reflux disease (GERD) ${ }^{8}$. In a retrospective review of 78 patients with COPD who were referred for videofluoroscopy swallowing studies, Good-Fratturelli and colleagues documented all accompanying medical conditions such as stroke, cervical osteophytes, and other neurologic disease ${ }^{13}$.

Three studies either described current medication use, or used certain medications as exclusionary criteria ${ }^{8,12,14}$. Two of these studies allowed the use of medications such as home oxygen therapy, oral and inhaled steroid therapy, and bronchodilator therapy during testing 8,14. Kobayashi and colleagues excluded patients taking corticosteroids ${ }^{12}$. Shaker and colleagues did report that patients were studied during acute exacerbations in the emergency room prior to medication use, but details on their usual medication regime were not provided ${ }^{11}$.

\section{Review of procedures}

Six of the 7 studies relevant to oropharyngeal swallowing and COPD used patients as subjects. Three of these 6 provided general descriptions of the swallowing impairment 8,13,15. Two focused on specific abnormalities of swallowing such as cricopharyngeal dysfunction ${ }^{14}$ and impairment of the swallowing reflex ${ }^{12}$. Shaker, $\mathrm{Li}$, and Ren et al. was the only study that compared the relationship between disordered respiration (respirography) and swallow (surface electromyography) using simultaneous measures ${ }^{11}$. Their data focused on the timing relationships between respiratory cycles and swallowing onset, peak and offset. Three studies investigated the relationship between swallowing and respiratory exacerbations 11,12,14. One study tested their subjects during an acute exacerbation ${ }^{11}$, while the other 2 studied patients who were described as prone to frequent exacerbations ${ }^{12,14}$.

The most commonly used test to assess swallowing was videofluoroscopy ${ }^{8,13-15}$. Two of these studies followed Logemann's ${ }^{52}$ suggested protocol for performing videofluorographic swallowing studies ${ }^{13,15}$. The remaining 2 studies that used videofluoroscopy as the measurement tool varied in procedure from 1 to 3 different bolus types, amount of bolus delivered, and in bolus consistency. Whether swallowing was spontaneous or elicited by command was not noted 2 studies ${ }^{8,14}$. Physical examination included a general physical evaluation ${ }^{8}$, head and neck evaluation ${ }^{14}$, and an examination specific to the oral musculature ${ }^{15}$. Additional instrumental evaluations to assess swallowing function included chest radiographs ${ }^{8}$, cineradiographs ${ }^{14}$, and spot films ${ }^{14}$. Mokhlesi, Logemann, Rademaker, Stangl, and Corbridge included a dysphagia symptom questionnaire in addition to videofluoroscopy and chest radiographs ${ }^{8}$. Two investigations used alternative tools to investigate swallowing. Kobayashi and colleagues used a nasal catheter to inject distilled water into the patients' pharynx to measure swallow delay in the elicitation of the swallowing response ${ }^{12}$. Shaker, $\mathrm{Li}$, and Ren et al. did simultaneous recording of the sEMG muscle activity associated with swallowing and the corresponding muscular activity of respiration using chest respirography ${ }^{11}$.

There was considerable variance in the length of the examination of swallowing function. Shaker, $\mathrm{Li}$, and Ren et al. included a 40 minute baseline monitoring period that was followed by a succession of swallowing tasks for normal young and elderly control groups ${ }^{11}$. Tasks for normals included reaching three different levels of exertion on a stationary bicycle that were determined by increasing respiratory rates while performing thirty swallowing tasks at each level. These swallows were compared to subjects in acute exacerbation who dry swallowed spontaneously (mean=14) in the emergency room prior to receiving medications to control their exacerbation. Ten patients were then retested between one week and one month in periods of respiratory stabilization ${ }^{11}$. 
Coelho followed 14 patients with COPD and oropharyngeal dysphagia for 18 months ${ }^{15}$. During this period they were given compensatory, behavioral swallowing strategies to obviate the risk of aspiration. However, details of the retesting results with videofluoroscopy, and the progress or lack of progress in swallowing competencies were not reported in those who did not aspirate. In a retrospective chart review of patients referred for COPD and suspected dysphagia, Good-Fratturelli and colleagues analyzed data collected over a 3-year period ${ }^{13}$. Stein and colleagues followed 10 patients with COPD using videofluoroscopy who underwent cricopharyngeal myotomy for restrictions of flow through the pharyngeal esophageal segment (PES) ${ }^{14}$. The exact time periods of post-operative evaluations were not reported.

\section{Conclusions}

Six of the 7 studies documented some type of disordered swallowing in patients with COPD ${ }^{8,11-15}$. This is not surprising since most of these studies examined patients who were identified as at risk for, or had overt signs of oropharyngeal swallowing dysfunction. Of the 78patientsstudied retrospectively, Good-Fratturelli and colleagues found that $85 \%$ had oropharyngeal swallowing dysfunction ${ }^{13}$. The most common types of swallowing problems in their sample were oral, vallecular, and piriform sinus stasis, and a delayed swallowing response. Fortytwo percent of these patients aspirated. Coelho described similar problems with stasis in the oral and pharyngeal stages in 14 patients with COPD and suspected dysphagia ${ }^{15}$. In his sample, $21 \%$ of patients consistently aspirated on videofluoroscopic examination. Mokhlesi and colleagues did not find any events of aspiration in 20 patients with stable COPD who were not selected because of potential risk for dysphagia ${ }^{8}$. None of the patients in this series showed signs of aspiration; although compared to normals, almost half performed compensatory airway closure maneuvers. They also found a trend toward lower laryngeal resting position, and a significantly lower mid-swallow laryngeal elevation in patients with COPD compared to healthy control subjects. Kobayashi and colleagues found that 22 of the 25 patients who were prone to exacerbations had delayed, and more prolonged swallowing responses; a finding not evident in those with stable COPD ${ }^{12}$. Stein, Williams, Grossman, Weinberg, and Zuckerbraun found cricopharyngeal dysfunction in 20 of 22 patients ${ }^{14}$. Older patients with more severe achalasia usually had poor lung function. Of the 10 patients who underwent myotomy, all 10 had improved cricopharyngeal function on postoperative videofluorographic studies. Respiratory-related symptoms such as wheezing and coughing showed little improvement, and 6 patients failed to show any improvement on pulmonary function tests. Shaker, $\mathrm{Li}$, and Ren et al.compared the respiratory and swallowing patterns in healthy young and elderly subjects to those with stable COPD in exacerbations and in stability ${ }^{11}$. They found that while rates of swallow were similar in all groups, the respiratory rates of both COPD groups were significantly higher. The respiratory phase interrupted by swallow in both groups of COPD patients was significantly different than controls. Patients with COPD were more likely to interrupt the inspiratory phase of respiration with swallowing and resume respiration with inspiration, rather than with expiration as seen in the normal controls.

What is the prevalence of oropharyngeal swallowing impairment in those patients with COPD? We could find no study that documented the prevalence of oropharyngeal dysphagia in patients with COPD. What are the characteristics of oropharyngeal swallowing disorders in patients with COPD? Six studies described the characteristics of the oropharyngeal swallow in patients with COPD ${ }^{8,11-15}$. What are the risk factors for developing oropharyngeal dysphagia in patients with COPD? Although the evidence is not strong, there is some indication that patients with COPD are more prone to oropharyngeal dysphagia during period of acute exacerbation. Is there any evidence that standard medical treatment for COPD improves oropharyngeal swallowing? We could find no studies that sought to answer this question.

COPD has a high prevalence in the population, and the number of those predicted to develop this disease with accompanying disability continues to rise world-wide. Because it is a disease of the cardiopulmonary system, and because respiratory decompensation may affect swallowing, it may be important to know how COPD affects swallowing safety. An incompetent swallow accompanied by pulmonary aspiration may actually be a precipitator of respiratory exacerbation in patients with COPD. Or exacerbations of COPD may be the precursor to swallowing disability and further decompensation of respiratory function leading to increased mortality.

This systematic review has shown that little is known about the relationship between COPD and oropharyngeal swallowing disability. It also has shown that comparisons of studies that have investigated COPD and oropharyngeal swallowing are difficult to compare due to differences in subject selection (particularly co-morbid diagnoses), poor control for medications, and lack of pulmonary function test (PFT) data on subjects enrolled in states of exacerbation (disease severity). Only in 
one study of the 7 reviewed was the diagnosis of COPD defined by universal guidelines ${ }^{53}$ using PFT test data ${ }^{8}$. Studies that focused on COPD and swallowing disorders were at evidence level $B$ and lower. Design flaws in level B studies such as poor subject selection criteria make generalization to the population of interest difficult.

Although this systematic review did not concentrate on the data pertaining to the prevalence of COPD and GERD, it is important not to ignore the high prevalence of GERD in this population as a concomitant contributor to oropharyngeal swallowing complaints ${ }^{54,55}$, and as an exacerbating factor in respiratory decompensation 14,30,32-34,41,47.

Future investigations into the relationship of COPD and oropharyngeal dysphagia need to focus on who may be at risk for developing dysphagia and its attendant complications. Parallel investigations should explore the question of whether undetected oropharyngeal dysphagia contributes to new exacerbations. Studies that explore the relationship between breathing and swallowing using simultaneous measures of swallow and respiration in homogenous groups of patients with COPD are particularly necessary. The use of manofluorgraphy ${ }^{56}$ in combination with the respiratory patterns associated with swallow will help delineate the relationships between structural displacements and the accompanying changes in pressure. Measurements of pressure are particularly important in delineating the pathophysiology of the pharyngoesophageal segment which may play a crucial role in the understanding of oropharyngeal dysphagia in patients with COPD. Finally, investigations that are designed to predict which factors of pulmonary function might precipitate oropharyngeal dysphagia and airway compromise are needed.

\section{CONCLUSION}

Although the evidence is not strong, it appears that patients with COPD are prone to oropharyngeal dysphagia during exacerbations. Future studies are needed to document the prevalence of oropharyngeal dysphagia in homogeneous groups of patients with COPD, and to assess the relationship between respiration and swallowing using simultaneous measures of swallowing biomechanics and respiratory function. These investigations will lead to a better understanding of the characteristics and risk factors of developing oropharyngeal dypshagia in patients with COPD.

\section{RESUMO}

Tema: disfagia orofaríngea em pacientes com doença pulmonar obstrutiva crônica. Objetivo: pacientes com Doença Pulmonar Obstrutiva Crônica (DPOC) podem ser vulneráveis à insuficiência respiratória que pode levar ao distúrbio de deglutição. Uma análise sistemática foi conduzida para investigar a relação entre a doença pulmonar obstrutiva crônica e a disfagia orofaríngea. Quarenta e sete artigos foram encontrados relativos à doença pulmonar obstrutiva crônica e disfagia. Cada artigo foi classificado utilizando metodologia baseada em evidências. Apenas 07 artigos dos 47 abordaram distúrbios de deglutição orofaríngea em pacientes com doença pulmonar obstrutiva crônica. Esta revisão encontrou poucos estudos que documentaram a relação entre os transtornos de deglutição orofaríngea e a doença pulmonar obstrutiva crônica. Não foram realizadas triagens de controle randomizadas. Conclusão: embora a prova não seja conclusiva, parece que os pacientes com doença pulmonar obstrutiva crônica são propensas à disfagia orofaríngea durante exacerbações. Futuros estudos são necessários para documentar a prevalência de disfagia orofaríngea em grupos homogêneos de pacientes com doença pulmonar obstrutiva crônica, e para avaliar a relação entre respiração e deglutição, utilizando medidas simultâneas de biomecânica de deglutição e função respiratória. Estas investigações conduzirão a uma melhor compreensão das características e fatores de risco do desenvolvimento de disfagia orofaríngea em pacientes com doença pulmonar obstrutiva crônica.

DESCRITORES: Doença Pulmonar Obstrutiva Crônica; Transtornos de Deglutição; Revisão 


\section{REFERENCES}

1. Martin-Harris B, Brodsky MB, Michel $Y$, Ford CL, Walters B, Heffner J. Breathing and swallowing dynamics across the adult lifespan. Arch Otolaryngol Head Neck Surg. 2005; 131(9):762-70.

2. Jean A. Brain stem control of swallowing: neuronal network and cellular mechanisms. Physiol Rev. 2001; 81(2):929-69.

3. Hadjikoutis S, Pickersgill TP, Dawson K, Wiles CM. Abnormal patterns of breathing during swallowing in neurological disorders. Brain. 2000; 123(9):1863-73.

4. Terzi $N$, Orlikowski $D$, Aegerter $P$, Lejaille $M$, Ruquet M, Zalcman G, et al. Breathing-swallowing interaction in neuromuscular patients: a physiological evaluation. Am J Respirat Crit Care Med. 2007; 175(3):269-76.

5. Kenny DJ, Casas MJ, McPherson KA. Correlation of ultrasound imaging of oral swallow with ventilatory alterations in cerebral palsied and normal children: preliminary observations. Dysphagia. 1989; 4(2):112-7.

6. de Bruin PF, de Bruin VM, Lees AJ, Pride NB. Effects of treatment on airway dynamics and respiratory muscle strength in Parkinson's disease. Am Rev Respir Dis. 1993; 148(6Pt1):1576-80.

7. Lim A, Leow L, Huckabee M, Frampton C, Anderson T. A pilot study of respiration and swallowing integration in Parkinson's disease: "on" and "off" levodopa. Dysphagia. 2008; 23(1):76-81.

8. Mokhlesi B, Logemann JA, Rademaker AW, Stangl CA, Corbridge TC. Oropharyngeal deglutition in stable COPD. Chest. 2002; 121(2):361-9.

9. Viegi G, Maio S, Pistelli F, Baldacci S, Carrozzi

L. Epidemiology of chronic obstructive pulmonary disease: health effects of air pollution. Respirology. 2006; 11(5):523-32.

10. Oxford Centre for Evidence -Based Medicine. Levels of evidence. [homepage na internet] 2001. Disponível em: URL: http://www.cebm.net

11. Shaker R, Li Q, Ren J, Townsend WF, Dodds WJ, Martin BJ, et al. Coordination of deglutition and phases of respiration: effect of aging, tachypnea, bolus volume, and chronic obstructive pulmonary disease. Am J Physiol Gastrointest Liver Physiol. 1992; 263(5):750-5.

12. Kobayashi S, Kubo H, Yanai M. Impairment of the swallowing reflex in exacerbations of COPD. Thorax. 2007; 62(11):1017.

13. Good-Fratturelli MD, Curlee RF, Halle JL. Prevalence and nature of dysphagia in VA patients with COPD referred for videofluoroscopic swallow examination. J Commun Disord. 2000; 33(2):93-110. 14. Stein M, Williams AJ, Grossman F, Weinberg AS, Zuckerbraun L. Cricopharyngeal dysfunction in chronic obstructive pulmonary disease. Chest. 1990; 97(2):347-52.

15. Coelho CA. Preliminary findings on the nature of dysphagia in patients with chronic obstructive pulmonary disease. Dysphagia. 1987; 2(1):28-31.

16. Harding SM. Oropharyngeal dysfunction in COPD patients: the need for clinical research. Chest. 2002; 121(2):315-7.

17. Burkhead LM, Sapienza CM, Rosenbek JC. Strength-training exercise in dysphagia rehabilitation: principles, procedures, and directions for future research. Dysphagia. 2007; 22(3):251-65. 18. Weiner P, Magadle R, Beckerman M, Weiner M, Berar-Yanay N. Comparison of specific expiratory, inspiratory, and combined muscle training programs in COPD. Chest. 2003; 124(4):1357-64.

19. Magadle R, McConnell AK, Beckerman M, Weiner $\mathrm{P}$. Inspiratory muscle training in pulmonary rehabilitation program in COPD patients. Respir Med. 2007; 101(7):1500-5.

20. Humbert IA, Robbins J. Normal swallowing and functional magnetic resonance imaging: a systematic review. Dysphagia. 2007; 22(3):266-75.

21. Cazzola M, MacNee W, Martinez FJ, Rabe KF, Franciosi LG, Barnes PJ, et al. Outcomes for COPD pharmacological trials: from lung function to biomarkers. Eur Respir J. 2008; 31(2):416-69.

22. Lacasse Y, Goldstein R, Lasserson TJ, Martin S. Pulmonary rehabilitation for chronic obstructive pulmonary disease. Cochrane Database Syst Rev. 2006; 4:1-47.

23. Kempainen RR, Savik K, Whelan TP, Dunitz JM, Herrington CS, Billings JL. High prevalence of proximal and distal gastroesophageal reflux disease in advanced COPD. Chest. 2007; 131(6):1666-71.

24. Mota S, Güell R, Barreiro E, Solanes I, RamirezSarmiento A, Orozco-Levi M, et al. Clinical outcomes of expiratory muscle training in severe COPD patients. Respir Med. 2007; 101(3):516-24.

25. Baker S, Davenport P, Sapienza C. Examination of strength training and detraining effects in expiratory muscles. J Speech Lang Hear Res. 2005; 48(6):1325-33.

26. Weiner P, Magadle R, Beckerman M, Weiner M, Berar-Yanay N. Specific expiratory muscle training in COPD. Chest. 2003; 124(2):468-73.

27. Kelly BN, Huckabee ML, Jones RD, Frampton CMA. The early impact of feeding on infant breathing-swallowing coordination. Respir Physiol Neurobiol. 2007; 156(2):147-53.

28. Ceriana $P$, Carlucci $A$, Navalesi $P$, Rampulla $C$, Delmastro $M$, Piaggi $G$, et al. Weaning from tracheotomy in long-term mechanically ventilated patients: feasibility of a decisional flowchart and clinical outcome. Intensive Care Med. 2003; 29(5):845-8. 
29. Kotani K, Tachibana K, Takamasu K. Investigation of the influence of swallowing, coughing and vocalization on heart rate variability with respiratory-phase domain analysis. Methods Inf Med. 2007; 46(2):179-85.

30. Moreau-Gaudry A, Sabil A, Baconnier P, Benchetrit G, Franco A. Use of computer and respiratory inductance plethysmography for the automated detection of swallowing in the elderly. Stud Health Technol Inform. 2005; 116:95-100.

31. Murry T, Tabaee A, Owczarzak V, Aviv JE. Respiratory retraining therapy and management of laryngopharyngeal reflux in the treatment of patients with cough and paradoxical vocal fold movement disorder. Ann Otol Rhinol Laryngol. 2006; 115(10):754-8.

32. Samson N, Duvareille C, St-Hilaire M, Clapperton V, Praud JP. CPAP inhibits non-nutritive swallowing through stimulation of bronchopulmonary receptors. Adv Exp Med Biol. 2008; 605:418-22.

33. Dua K, Bardan E, Ren J, Sui Z, Shaker R. Effect of chronic and acute cigarette smoking on the pharyngo-upper oesophageal sphincter contractile reflex and reflexive pharyngeal swallow. Gut. 1998; 43(4):537-41.

34. Colodny N. Effects of age, gender, disease, and multisystem involvement on oxygen saturation levels in dysphagic persons. Dysphagia. 2001; 16(1):48-57.

35. Vitacca M, Callegari G, Sarva M, Bianchi L, Barbano L, Balbi B, et al. Physiological effects of meals in difficult-to-wean tracheostomised patients with chronic obstructive pulmonary disease. Intensive Care Med. 2005; 31(2):236-42.

36. Schols A, Mostert R, Cobben N, Soeters P, Wouters $E$. Transcutaneous oxygen saturation and carbon dioxide tension during meals in patients with chronic obstructive pulmonary disease. Chest. 1991; 100(5):1287-92.

37. Hannhart B, Michalski H, Delorme N, Chapparo G, Polu JM. Reliability of six pulse oximeters in chronic obstructive pulmonary disease. Chest. 1991; 99(4):842-6.

38. Brown SE, Casciari RJ, Light RW. Arterial oxygen saturation during meals in patients with severe chronic obstructive pulmonary disease. South Med J. 1983; 76(2):194-8.

39. Sai T, Isono $S$, Nishino T. Effects of withdrawal of phasic lung inflation during normocapnia and hypercapnia on the swallowing reflex in humans. $J$ Anesth. 2004; 18(2):82-8.

40. Mokhlesi B, Morris AL, Huang CF, Curcio AJ, Barrett TA, Kamp DW. Increased prevalence of gastroesophageal reflux symptoms in patients with COPD. Chest. 2001; 119(4):1043-8.
41. Raiha IJ, Ivaska K, Sourander LB. Pulmonary function in gastro-oesophageal reflux disease of elderly people. Age Ageing. 1992; 21(5):368-73.

42. Casanova C, Baudet JS, del Valle Velasco M, Martín JM, Aguirre-Jaime A, de Torres JP, et al. Increased gastro-oesophageal reflux disease in patients with severe COPD. Eur Respir J. 2004; 23(6):841-5.

43. Rascon-Aguilar IE, Pamer $M$, Wludyka $P$, Cury J, Coultas D, Lambiase LR, et al. Role of gastroesophageal reflux symptoms in exacerbations of COPD. Chest. 2006; 130(4):1096-101.

44. Wheeler K, Chiara T, Sapienza C. Surface electromyographic activity of the submental muscles during swallow and expiratory pressure threshold training tasks. Dysphagia. 2007; 22(2):108-16.

45. Chapman KR, Rebuck AS. Dysphagia as a manifestation of occult hypoxemia: the role of oximetry during meal times. Chest. 1991; 99(4):1030-2.

46. Field SK, Evans JA, Price LM. The effects of acid perfusion of the esophagus on ventilation and respiratory sensation. Am J Respir Crit Care Med. 1998; 157(1):1058-62.

47. Sapienza CM, Wheeler K. Respiratory muscle strength training: functional outcomes versus plasticity. Semin Speech Lang. 2006; 27(4):236-44. 48. Kim J, Sapienza CM. Implications of expiratory muscle strength training for rehabilitation of the elderly: tutorial. J Rehabil Res Dev. 2005; 42(2):211-24.

49. Martin-Harris B. Clinical implications of respiratory-swallowing interactions. Curr Opin Otolaryngol Head Neck Surg. 2008; 16(3):194-9.

50. Carnaby-Mann GD, Crary MA. Examining the evidence on neuromuscular electrical stimulation for swallowing: a meta-analysis. Arch Otolaryngol Head Neck Surg. 2007; 133(6):564-71.

51. Mokhlesi B. Clinical implications of gastroesophageal reflux disease and swallowing dysfunction in COPD. Am J Respir Med. 2003; 2(2):117-21.

52. Logemann J. Evaluation and treatment of swallowing disorders. San Diego, CA: College-Hill Press; 1983.

53. Celli BR, Snider GL, Heffner JE. American Thoracic Society statement: standards for the diagnosis and care of patients with chronic obstructive pulmonary disease. Am J Respir Crit Care Med. 1995; 152:S77-S120.

54. Torrico S, Kern M, Aslam M, Narayanan S, Kannappan A, Ren J, et al. Upper esophageal sphincter function during gastroesophageal reflux events revisited. Am J Physiol Gastrointest Liver Physiol. 2000; 42(2):G262-G7. 
55. Mendell DA, Logemann JA. A retrospective analysis of the pharyngeal swallow in patients with a clinical diagnosis of GERD compared with normal controls. Dysphagia. 2002; 17(3):220-6.
56. McConnel FM, Hester TR, Mendelsohn MS, Logemann JA. Manofluorography of deglutition after total laryngopharyngectomy. Plast Reconstr Surg. 1988; 81(3):346-51.

DOI: 10.1590/S1516-18462009005000040

RECEBIDO EM: 25/01/2009

ACEITO EM: 13/07/2009

Endereço para correspondência:

Michael Groher

Department of Communicative Disorders

University of Redlands

1200 E. Colton Ave.

Redlands, CA, USA, 92374

E-mail: michael_groher@redlands.edu 